\title{
La salud en tiempos de guerra
}

\author{
Instituto de Derechos Humanos de la UCA (IDHUCA)
}

\section{Resumen}

La salud es un derecho de toda ciudadano salvadoreño. Aún antes del conflicto bélico actual, el sistema de salud del país era deficiente e inadecuado. Al igual que muchos otros países subdesarrollados, en El Salvador no se dedicaban suficientes recursos humanos, técnicos, y económicos al desarrollo de un sistema adecuado de salud; tampoco hubo un buen uso de los recursos disponibles ni una planificación de largo plazo con miras a mejorar la salud de las mayorías populares.

El Salvador es distinto de los demas países subdesarrollados, porque el conflicto bélico de más de 11 años de duración ha aumentado la necesidad y la demanda de los cuidados de la salud, ha acelerado el deterioro de las condiciones de la salud, y ha hecho aún más visible y sentida la falta de una buena salud entre las mayorías populares. Si tomamos las condiciones de salud de la población y los esfuerzos del gobierno por proveer y cubrir las necesidades básicas de la población salvadoreña como un indicador de una democracia real, todavía estamos muy lejos de ella. Estamos ya muy mal en el área de salud y los esfuerzos para cambiar y mejorar no son suficentes.

El deterioro de los servicios de la salud en El Salvador se debe sobre todo a factores controlados por el gobierno y la Fuerza Armada. Es necesario redefinir las prioridades y hacer cambios estructurales significativos para mejorar la salud del pueblo salvadoreño y así llegar a una paz verdadera. Las necesidades de salud son parte fundamental de las necesidades básicas insatisfechas que se encuentran en la raíz del conflicto.

\section{Introducción}

Desde hace varios meses hemos estado escuchando advertencias sobre la eminente llegada de una enfermedad mortal a El Salvador, el cólera.
Como se transmite fácilmente, se calcula que el cólera alcanzará proporciones epidémicas dentro de poco tiempo. En un país donde las condiciones de salud son buenas, el cólera no causaría tanto 
pánico y con unas precauciones mínimas podría ser controlado. Pero en El Salvador, un país con unas condiciones de salud precarias, los riesgos son muy grandes y las consecuencias de una epidemia de cólera podrían ser trágicas.

El obispo auxiliar de San Salvador calificó la posible llegada del cólera al país como un desafío para los salvadoreños. "El cólera entraría entre nosotros como en un terreno totalmente abandonado porque la infraestructura de salud es desastrosa," dijo a la prensa el 11 de agosto. Agregó que como la mayoría de la población vive en condiciones infrahumanas, en este sector, precisamente, se producirán la mayoría de las víctimas de la epidemia. "Como lo hemos dicho ya en otras oportunidades, si el cólera llega al país, Dios quiera que no, puede ser fatal y va a dejar al descubierto cómo es que está organizada esta sociedad y cómo, por lo tanto, no podemos hablar de democracia real".

Este artículo examina este terreno total e intencionalmente abandonado. Analiza las pésimas condiciones de salud del pueblo salvadoreño y la desastrosa infraestructura de salud. Los datos provienen de las tendencias de las condiciones de la salud y de los principales problemas de la misma en El Salvador, a partir de los estudios y diagnósticos hechos durante las dos últimas décadas. Asimismo, analiza el impacto del conflicto bélico en las condiciones de salud. Sin embargo, no pretende dar soluciones a toda esta problemática tan compleja, pero sí plantea la necesidad de conocer mejor la realidad y de identificar y enfrentar las prioridades, según las necesidades de salud de las mayorías populares.

2. Las responsibilidades del Estado: las bases legales

La salud no es una simple falta de enfermedad, sino un "estado de completo bienestar físico, mental y social"'. La salud está afectada por otras necesidades básicas: la alimentación, el vestido, la vivienda y la educación; por las condiciones de sanidad ambiental y por la oferta de cuidados de salud y el acceso a ellos. La salud no es un concepto aislado. La Organización Mundial de la Salud afirma que, "el desarrollo social y económico incluye el desarrollo en el sector salud, todos los sectores de la economia tienen un componente sanitario tan importante que es imposible no tomarlo en consideración. La salud influye en el resto del complejo social y económico y a su vez recibe la influencia de éste ${ }^{2}$.

El Salvador asumió obligaciones legales a nivel internacional y nacional para usar sus recursos eficazmente y dotar de cuidados médicos a sus ciudadanos, expandir los servicios de salud y mejorar las condiciones de la salud pública. Por ejemplo, el derecho a los cuidados de salud es uno de los principios de la Declaración Universal de Derechos Humanos, la Carta [Magna] de las Naciones Unidas, la Carta de los Estados Americanos (enmendada por el Protocolo de Buenos Aires), la Convención Americana Sobre Derechos Humanos y el Pacto Internacional de Derechos Económicos, Sociales y Culturales. El Pacto Internacional de Derechos Económicos, Sociales y Culturales espeficifica el derecho a la salud y establece los criterios para medir los esfuerzos del Estado para promover y lograr dicho derecho. Como signatario del Pacto Internacional, el gobierno salvadoreño tiene la obligación legal para reducir la mortalidad y morbilidad infantil, para mejorar las condiciones ambientales que afectan a la salud pública, para controlar las enfermedades transmisibles y para desarrollar los servicios de salud hasta que la población entera tenga acceso a cuidados médicos cuando los necesite.

Los convenios de Ginebra (1949) y sus protocolos adicionales (1977) establecen los lineamientos para el respecto de la ayuda humanitaria, para los trabajadores de salud y los trabajadores religiosos, para los heridos y enfermos, para los prisioneros de guerra, para las unidades médicas y para otros servicios de salud durante un conflicto bélico. Estos tratados internacionales constituyen las bases de los principios de la neutralidad médica.

La ley fundamental de El Salvador también requiere que el Estado provea servicios de salud. Es "obligación del Estado asegurar a los habitantes de la República, el goce de la libertad, la salud, la cultura, el bienestar económico y la justicia 
social," según el artículo 1 de la Constitución. El artículo 65 dice, "La salud de los habitantes de la República constituye un bien público. El Estado y las personas están obligados a velar por su conservación y restablecimiento. El Estado determinará la Política Nacional de Salud y controlará y supervisará su aplicación".

Por lo tanto, no estamos hablando arbitrariamente, sino de obligaciones y responsabilidades formales asumidas por el Estado. Ahora veamos la situación de la salud en El Salvador, para comprobar cómo el Estado está cumpliendo con sus obligaciones y responsabilidades.

\section{La pésima realidad}

Un breve diagnóstico de la salud del pueblo salvadoreño y de las condiciones de salud de las dos últimas décadas, muestra múltiples problemas y un deterioro notable. Las condiciones de salud en las cuales vive el pueblo salvadoreño se encuentran sumamente determinadas por las características de la población, la tenencia de la tierra y por otros factores socioeconómicos.

\subsection{Las características de la población}

En 1991, El Salvador tiene una población de $5,251,678$ habitantes. Con una densidad poblacional de 250 habitantes por kilómetro cuadrado y más de 708 personas por kilómetro cuadrado de tierra cultivable, El Salvador es el país más densamente poblado de Centroamérica ${ }^{3}$. De hecho, las condiciones de vida son propicias para la transmisión de enfermedades infecciosas, como el sarampión, el cólera y las enfermedades respiratorias agudas de la niñez. La raíz de los problemas de la salud es la escasa y mala distribución de la tierra.

La población salvadoreña es mayoritariamente joven. Cerca del 50 por ciento es menor de 15 años y los menores de 20 años son casi el 60 por ciento del total de la población ${ }^{4}$. La tasa de crecimiento anual es del 2.4 por ciento ${ }^{5}$. Se calcula que la población va a aumentar hasta llegar a 11.3 millones en el año 2025, y va a duplicarse dentro de los próximos cuarenta afios. El crecimiento poblacional implica un incremento en la demanda de los cuidados y servicios de salud, de alimen-

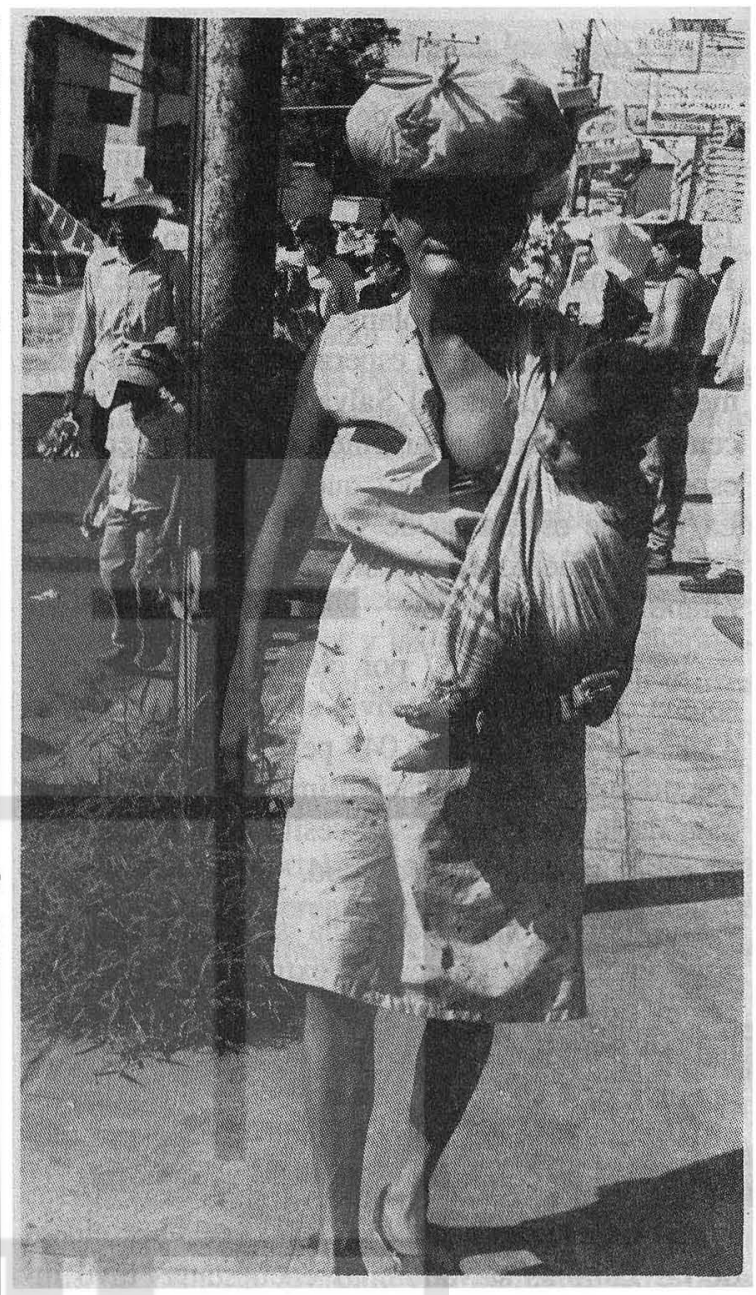

tación, de vivienda y de otras necesidades básicas a corto y mediano plazo.

Las mujeres de 14 a 45 affos de edad conforman un grupo de alto riesgo en la condición de embarazo y lactante. La población masculina y femenina que se ubica entre 0 a 14 afios de edad es la que más requiere de atención médica, porque es la más vulnerable a las enfermedades infecciosas y porque sus niveles de frecuencia de las enfermedades es mayor que el de otras edades. El 51 por ciento de la población era del sexo masculino en la década de los setenta, pero en 1991 se informó que, tras diez años de conflicto armado y la emigración de más de un millón de salvadoreños, ahora hay más mujeres que hombres en el país, según datos aproximados de la unidad de estadis- 
tica y censo'.

Según el Ministerio de Planificación, la esperanza de vida al nacer ha disminuido durante la última década. Em 1950-1955, era de 44 años; en 1970-1975, aumentó a 56.55 affos; pero en 19801985 disminuyó a 50.74 años $^{7}$. A finales de la década de los ochenta, solamente 4 de los 35 países de las Américas tenian esperanzas de vida al nacer menores que las de El Salvador; entre los países centroamericanos, solamente Guatemala tiene una esperanza de vida menor que la de El Salvador. La tasa de esperanza de vida al nacer en el país está fuertemente condicionada por la mortalidad infantil y la violencia.

En 1990 , el 56.87 por ciento $(2,986,629$ personas) de la población vivía en zonas rurales y el 43.13 por ciento $(2,265,049$ personas $)$ vivía en zonas urbanas'. Esta situación implica que la población de la zonas rurales necesita mayor cuantía y acceso a los servicios de salud.

La población salvadoreña se caracteriza por altos índices de pobreza y extrema pobreza, los cuales tienen un impacto muy negativo en la salud. El 86 por ciento de los salvadoreños vive en la pobreza (Cuadro 1). Según el Ministerio de Planificación, más del 60 por ciento de los salvadoreños vive en condiciones de extrema pobreza.

En un estudio hecho en 1989 , el 63 por ciento de las familias salvadoreñas encuestadas tuvo ingresos menores de 300 colones (37.50 dólares) mensuales, y no pudo comprar los alimentos básicos necesarios para satisfacer los requisitos mínimos alimenticios de calorias y proteínas $(2,260$ calorías y 60 gramos de proteína/persona/día) ${ }^{10}$. Los mayores índices de pobreza y de extrema pobreza, con desnutrición crónica, siguen presentándose en las áreas rurales. Las mujeres de las áreas rurales sufren aún más las consecuencias de la pobreza. La única fuente de ingresos para la mayoría de las personas de las zonas rurales proviene de la agricultura, la cual no es muy bien renumerada. Hay un círculo vicioso: el nivel bajo de ingresos de muchas de las familias salvadoreñas las lleva a una dieta desbalanceada e insuficiente, la cual les lleva, a su vez, a la desnutrición prevalente y a una alta tasa de morbididad y de mortalidad. La

\section{Cuadro 1 \\ Incidencia de la pobreza rural y urbana, 1985-1987 \\ Familias pobres como $\%$ del total}

\section{Pobreza}

$\begin{array}{lllll}\text { Costa Rica (1986) } & 25 & 12 & 19 & 70\end{array}$

$\begin{array}{llllll}\text { Nicaragua (1983) } & 82 & 48 & 64 & 60\end{array}$

$\begin{array}{llllll}\text { Honduras (1988) } & 89 & 57 & 78 & 75\end{array}$

$\begin{array}{lllll}\text { Guatemala (1986-87) } & 93 & 67 & 83 & 70\end{array}$

$\begin{array}{lllll}\text { El Salvador (1985) } & 92 & 80 & 86 & 51\end{array}$

Extrema pobreza

$\begin{array}{lllll}\text { Costa Rica (1986) } & 13 & 5 & 10 & 73\end{array}$

$\begin{array}{lllll}\text { Nicaragua (1983) } & 49 & 18 & 32 & 72\end{array}$

$\begin{array}{lllll}\text { Honduras (1988) } & 70 & 27 & 55 & 83\end{array}$

$\begin{array}{lllll}\text { Guatemala (1986-87) } & 70 & 55 & 65 & 68\end{array}$

$\begin{array}{lllll}\text { El Salvador (1985) } & 60 & 40 & 49 & 57\end{array}$

Fuente: R. Menjívar y J. D. Trejos (1990), La pobreza en América Central. FLACSO. San José, Costa Rica, pp. 565-566.

Nota: Pobreza se refiere a la insuficiencia del ingreso para mantener un nivel de consumo básico (alimentos, vivienda, ropa); extrema pobreza se refiere a la insuficiencia del ingreso para mantener el consumo de alimentos básicos.

incidencia de las enfermedades aumenta por el ambiente insalubre en que las familias empobrecidas viven.

Hasta diciembre de 1971, sólo el 24 por ciento de los habitantes rurales tenía agua potable y el 8 por ciento usaba letrina ${ }^{11}$. Una década después, el 22 por ciento de los habitantes rurales tiene agua potable. En los años ochenta, solamente el 10 por ciento de las viviendas tiene sistema de alcantarillado y disposición de excretas en las comunidades marginales del área metropolitana de San Salvador $^{12}$. En octubre de 1989, ANDA registró que solamente el 57 de la población urbana tiene agua potable y el 43 por ciento no tiene, lo cual muestra un deterioro sobre las dos décadas anteriores. En las zonas urbanas, no hay sistemas adecuados para el tratamiento de aguas negras, de aguas ser- 
vidas, de la basura, ni de otros desperdicios. Prácticamente, todos los ríos del país están contaminados por desechos humanos, animales o aguas industriales ${ }^{13}$.

Globalmente, el 44 por ciento de las familias salvadorentas no posee agua potable y el 43 por ciento no cuenta con adecuada eliminación de excretas $^{14}$. En las áreas rurales, se estima que el $\mathbf{9 0}$ por ciento de las familias no tiene agua potable y el 70 por ciento carece de letrinas u otro sistema para la eliminación de excretas. Los índices varían según áreas geográficas. De acuerdo a un estudio de la FAO, en 1985, los departamentos con las peores condiciones de saneamiento ambiental eran Cabañas (solamente el $\mathbf{1 0 . 8}$ por ciento de la población cuenta con un servicio sanitario), Cuscatlán (33.7 por ciento), Chalatenango ( 26.4 por ciento) y Morazán (29.3 por ciento). La falta de agua trae un sinnúmero de problemas para la higiene, la limpieza y la salud.

En 1971, el 84.6 por ciento de las viviendas en El Salvador tenía dos habitaciones o menos, y 58.1 por ciento de las viviendas tenía 5 ó más personas viviendo en ellas ${ }^{15}$. Veinte años después, el 85 por ciento de las familias rurales vive en hogares de una sola habitación ${ }^{16}$. Un estudio de FUSADES determinó que en 1985 hubo una déficit habitacional de 584,434 unidades, de las cuales el Estado y las compañías privadas cubrían apenas el 2.9 por ciento de las necesidades anuales. El resto de las viviendas es construido por los sectores populares e informales, usando cualquier material y sitio. Por las condiciones de la vivienda y la alta densidad poblacional, fácilmente se generan puntos de contagio y transmisión de enfermedades infecciosas.

\subsection{Las tendencias de mortalidad y morbilidad}

A nivel mundial se han establecido indicadores a través de los cuales se puede evaluar la salud de un pueblo. Pero al analizar las tendencias de mortalidad y morbilidad en El Salvador, nos encontramos con la existencia de pocos datos estadísticos confiables desde 1980 . No se ha hecho un censo de la población desde $1971^{17}$. Las fuentes oficiales utilizan solamente aquellos datos sobre nacimien- tos y defunciones registrados en los centros hospitalarios, en los centros de salud y en otros establecimientos, dejando fuera muchos casos no registrados. Por ejemplo, un porcentaje bajo de muertes, menos del $\mathbf{5 0}$ por ciento, cuenta con certificación médica y solamente tales casos son usados para determinar la tasa de mortalidad. Por lo tanto, los valores están subestimados y hay una confiabilidad limitada para el análisis. Las fuentes oficiales tienen la tendencia a extrapolar mejoras no probadas científicamente.

Durante los afios previos al conflicto armado, los indicadores más generales - las tasas de mortalidad infantil, los índices de morbilidad, la esperanza de vida al nacer y las tasa de desnutriciónse encontraban por debajo del promedio de países latinoamericanos ${ }^{18}$.

\subsubsection{La mortalidad infantil}

La tasa de mortalidad infantil, o sea, el número de niños que mueren dentro de su primer año de vida, sigue siendo alto en El Salvador, aunque hay mucha discrepancia entre diferentes fuentes sobre la cifra actual. CELADE registra $\mathbf{4 2 . 2}$ muertes de niños menores de un año de edad por cada mil nacidos vivos, durante el período de 1980-1985 ${ }^{19}$. Otras fuentes señalan que, en 1989, la tasa de mortalidad infantil es de 65 muertes por cada mil nacidos vivos. Una tasa dos o tres veces mayor que la tasa de mortalidad infantil en los otros países centroamericanos, incluyendo a Costa Rica y Panamá. A pesar de las diferencias entre varias fuentes de información, el nivel de la mortalidad infantil en El Salvador es alto y está dentro de los más altos del continente latinoamericano.

La mayor mortalidad infantil se encuentra en las áreas rurales. Un estudio que registra una tasa de mortalidad infantil global de 71.0, mostró que la tasa de mortalidad infantil era menor en el área metropolitana (47.8 muertes por mil nacidos vivos) y el resto de la zona urbana (63.4), pero era mayor en la zona rural $(80.9)^{20}$. De esto se deduce la necesidad de priorizar los esfuerzos para reducir la mortalidad infantil en las áreas rurales.

Según la UNICEF, el 59 por ciento de todos los muertos en El Salvador, incluyendo las vícti- 
mas de la guerra, son niños menores de cinco años de edad. Las dos terceras partes de estas víctimas son nifios menores de un año de edad, y el 41 por ciento de esta mortalidad infantil es de niffos que mueren durante los primeros treinta dias de vida. El 14 por ciento de los niffos salvadoreños muere en el momento del parto, una de las tasas de mortalidad más altas del mundo.

Considerando la tasa de bajo peso al nacer, o sea, el número de niños nacidos vivos con un peso de 2.5 kilogramos o menos, El Salvador ocupa el cuarto lugar entre 35 paises de las Américas analizados. El bajo peso al nacer se relaciona bastante con la mortalidad infantil ${ }^{21}$.

La mayor parte de la mortalidad infantil y de nifios entre uno y cuatro años de edad se debe a las enfermedades respiratorias y la diarrea $\mathrm{El}$ acceso al agua potable y a provisiones de saneamiento ambiental, por ejemplo el uso de letrinas y prácticas de higiene, tienen un impacto significativo para el control de las enfermedades diarréicas. Otras intervenciones que reducen la morbilidad y la mortalidad causadas por la diarrea incluyen la lactancia materna, las mejorias nutricionales y las inmunizaciones contra el sarampión ${ }^{22}$.

\subsubsection{La mortalidad materna}

En 1989, la tasa de mortalidad materna en El Salvador era una de las más elevadas de Centroamérica, siendo ésta de 1.4 por cada mil nacidos vivos para $1989^{23}$.

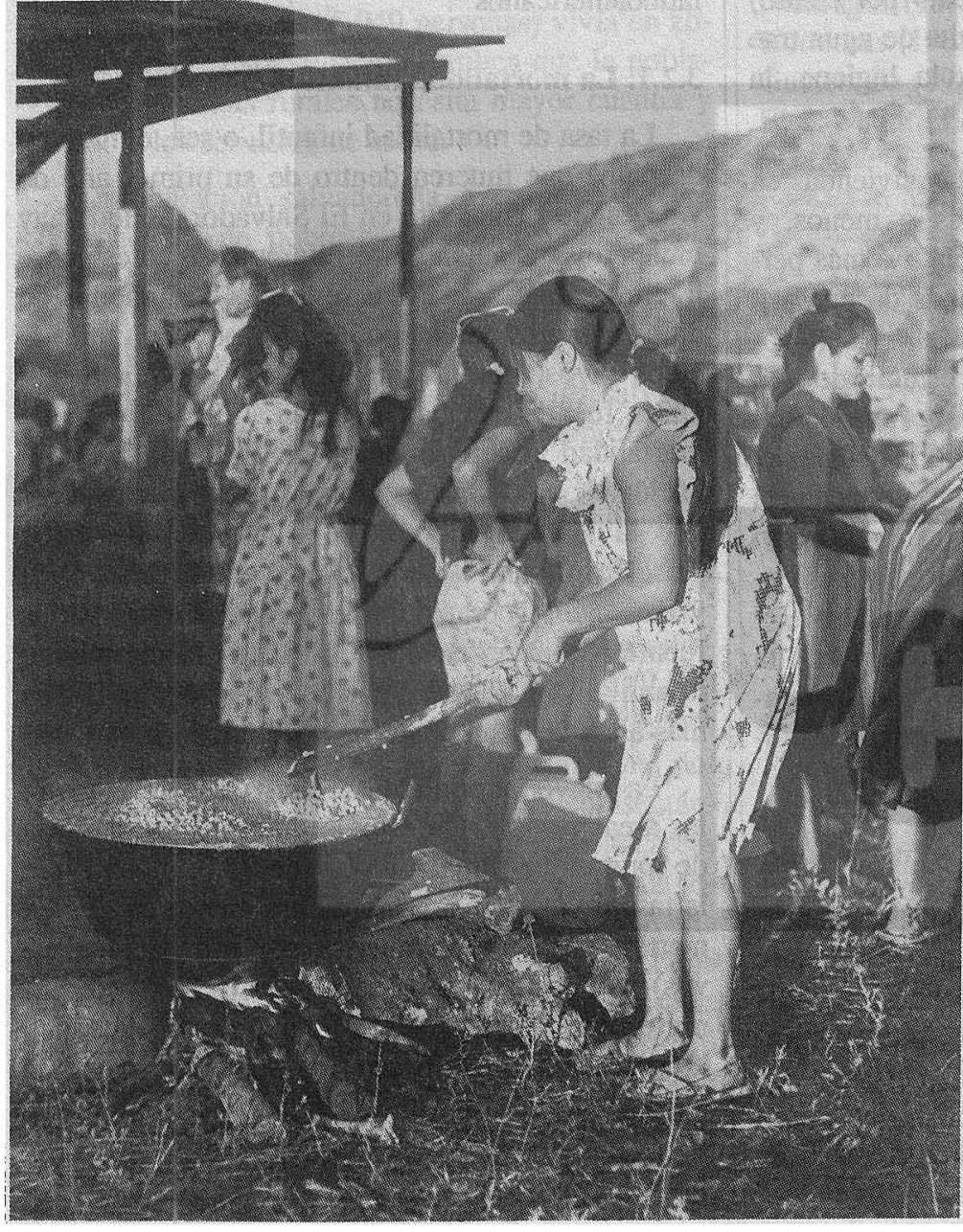

\subsubsection{La mortalidad general}

Se estima, en base a cifras oficiales, que la tasa bruta de mortalidad habría ascendido de 7.9 por cada mil habitantes en 1975 , a 8.6 en 1980 , y hasta a 12.6 muertes por mil habitantes en 1980 si se consideran las personas que murieron a consecuencia del conflicto armado. En 1982, se registraron 8.2 muertes por cada mil habitantes, en $1986,10.8$ por cada mil habitantes $y$, en $1990,8.4^{24}$. La población desplazada presenta tasa brutas de mortalidad y morbilidad tres veces más alta que la población no desplazada (21 por mil, versus 6.9 por mil) ${ }^{25}$.

Una aproximación indirecta a la situación de mortalidad se puede obtener a través del comportamiento de las diez primeras causas de defunción en el país. Hasta 1979, las denominadas "enteritis y otras enfermedades diarréicas" ocuparon el primer lugar como causa de defunción. Para 1980, ése lugar lo ocupa, "homicidios y lesiones inflingi- 
das intencionalmente por otra persona", una seffal sobre los niveles que la violencia ha alcanzado. La segunda causa de defunción la constituyeron "ciertas afecciones originadas en el período perinatal", es decir, afecciones en el feto, originadas a partir de la 28: semana de embarazo y antes de cumplir los 28 días de nacido. Este dato muestra directamente el resultado de la disminución de la atención de salud en el período prenatal y las criticas condiciones en el momento del parto, la no atención de los centros asistenciales, el pobre estado de salud y nutrición de las madres y de los fetos, y una salubridad ambiental deficiente. Desafortunamente, la Memoria del Ministerio de Salud Pública y Asistencia Social del 1990-1991 no incluye información más específica sobre las primeras diez causas de muerte en El Salvador.

\section{Cuadro 2}

Las diez primeras causas de muerte (1971) (En porcentajes)

\section{Enteritis y otras enfermedades diarréicas 14.6 \\ Bronquitis, enfisema y asma \\ Homicidios y lesiones provocadas intencionalmente por otras personas \\ Otras enfermedades del aparato digestivo \\ Otras neumonias \\ Tumores malignos \\ Enfermedades cerebrovasculares \\ Avitaminosis y otras deficiencias nutricionales \\ Anemias \\ Accidentes de vehículos de motor

Fuente: Ministerio de Salud Pública y Asistencia Social. 1972. Memoria 1971-1972. San Salvador.

En resumen, la mayoría de la población salvadoreña continúa enfermándose y continúa muriendo por causas que podrían evitarse con relativa facilidad por medio de medidas preventivas.

\subsubsection{Las enfermedades transmisibles}

Las cinco primeras causas de enfermedades transmisibles notificables, registradas en 1990 son, en orden descendente, el parasitismo intestinal, la
Cuadro 3

Las diez primeras causas de muerte (1981)

(En porcentajes)

Accidentes y violencia

31.3

Causas no definidas

19.2

Accidentes durante el parto y

el periodo perinatal

10.9

Infecciones y parásitos $\quad 10.7$

Enfermedades del sistema circulatorio $\quad 6.9$

Sub Total

79.0

Otras enfermedades

21.0

Fuente: World Health Organization (WHO). 1981. World Health Statistics Annual. Ginebra.

influenza o gripe, las enfermedades diarréicas, la disenteria amebiana, y la tricomoniasis vaginal ${ }^{26}$.

La diarrea causa más del 30 por ciento de la mortalidad infantil, el 16.99 por ciento de la mortalidad entre personas de todas edades, y es la principal causa de mortalidad entre niños menores de cinco años en El Salvador ${ }^{27}$. La diarrea tiene su incidencia mayor entre los niños menores de un año de edad en las zonas rurales ${ }^{28}$. El 40 por ciento de los niños menores de un año de edad que son hospitalizados adolecen de diarrea y deshidratación.

La diarrea se propaga por falta de acceso a agua potable, por falta de letrinas y de otro sistema adecuado para la disposición de las excretas, por la falta de un control de alimentos, y por la falta de condiciones y práticas higiénicas. Para reducir la mortalidad y morbilidad causadas por la diarrea, hay que analizar sus causas y enfrentarlas.

El 19 de agosto de 1991, fue confirmado el primer caso de cólera de este siglo en El Salvador. El Ministro de Salud, coronel y doctor Lisandro Vásquez Sosa confirmó oficialmente que un hombre de treinta años, que padece de alcoholismo crónico y vive alimentándose de los desperdicios de alimentos que encuentra en los basureros del barrio San Jacinto (San Salvador), es la primera víctima del país. La víctima se encuentra recuperándose en el Hospilal Rosales de San Salvador. Desde el 24 de julio hasta el 19 de agosto, el Mi- 
nisterio de Salud y Asistencia Social ha investigado unos 5,243 casos de diarrea y de estos, 31 resultaron sospechosos de cólera, pero posteriormente fueron desechados todos menos un caso positivo $^{29}$. El Ministerio de Salud mantiene una estricta vigilancia sobre todos los casos de diarrea en el país y está en contacto permanente con los hospitales, con los centros y las unidades de salud, con el Hospital de ANTEL, con el Hospital Militar, con los centros del ISSS y los hospitales privados.

Desde hace más de seis meses sabíamos que la llegada del cólera a El Salvador era eminente. Después del brote en Perú, en enero de 1991, se fueron confirmado casos de cólera en Ecuador, Brazil, Chile y Colombia. De Sudamérica, el cólera saltó a México, donde se comenzaron a confirmar casos del cólera en junio. La Organización Panamericana de la Salud informó de la existencia de 174,985 casos de cólera en América Latina hasta finales de mayo de 1991, de los cuales 169,265 fueron registrados por el gobierno de Perú, donde hubo 1,244 fallecimientos a causa de la enfermedad. El 24 de julio, fue oficialmente confirmado el primer caso del cólera en Centroamérica, en Guatemala, en la zona próxima a la frontera con México ${ }^{30}$. El mismo día, el Ministro de Salud de El Salvador anunció que nuestro país había sido declarado en estado de emergencia nacional por la eminente llegada de la peste. Según el ministro, "el dolor es el mismo para un rico que para un pobre... hay que superar las diferencias políticas". Advirtió que 25 de cada mil personas podían morirse del cólera, siendo los habitantes de las zonas marginales las más afectadas. El 28 de julio, el FMLN hizo un llamado a la población para combatir el cólera. Según las fuerzas guerrilleras, sus trabajadores de salud van a visitar las poblaciones civiles en las zonas bajo control del FMLN para dar orientación sobre el cólera.

El crecimiento desordenado de las ciudades, la falta de agua potable, el no tratamiento o tratamiento inadecuado de las excretas y la contaminación de los ríos, propician el contagio con mayor rapidez. El área metropolitana de San Salvador, por ejemplo, carece de una planta de tratamiento y las aguas servidas saltan de los colectores al río
Acelhuate, que contamina otros cuerpos de agua, inclusive el río Lempa. Hay más de 600,000 personas viviendo en las comunidades marginales del área metropolitana de San Salvador, muchas de ellas al lado del río, en barrancos y en condiciones precarias e insaludables.

Los funcionarios del Ministerio de Salud y Asistencia Social están preocupados. Según el Departamento de Epidemología, unos 162,500 salvadoreños podrían contraer la enfermedad, con una propagación explosiva, y de esos, por lo menos 1,500 podrían morir ${ }^{31}$. El cólera se propaga con tanta rapidez que puede llegar a producir 12,000 casos por semana con un considerable porcentaje de muertos. "Cólera causa más víctimas que la guerra, dice salud," según El Diario de Hoy ${ }^{32}$.

Diecisiete organizaciones populares de San Salvador se unieron para formar el Comité de Organizaciones Populares contra el Cólera. El 9 de agosto de 1991 dieron inicio a una campaña de prevención del cólera a nivel naciónal, la cual se realizará en comunidades marginales y campesinas. Hicieron un llamado tanto al ejército como a la guerrilla para que no obstaculice la labor de dichas organizaciones ${ }^{33}$.

Una epidemia de cólera puede tener repercusiones políticas. Por ejemplo, las altas tasas de mortalidad causadas por enfermedades infecciosas en Inglaterra y específicamente cuatro epidemias de cólera, ocurridas entre 1830 y 1866, sembraron mucho descontento público. Como las epidemias de cólera afectaron a la clase media (que tenía los votos), además de afectar a los pobres (que no tenían voto), el parlamento inglés fue obligado a aprobar una ley sobre salud pública en 1848, creando una junta general de salud y juntas locales, así como también provisiones para velar por la salud de la población en general ${ }^{34}$.

Al prolongarse la epidemia del cólera en Perú, en 1991, hubo mucha controversia sobre la forma de manejar la información disponible al público. Tras una confrontación entre el Ministro de Salud, Carlos Vidal, y el presidente, Alberto Fujimori, aquél renunció.

Otras enfermedades transmisibles que ya fueron controladas, erradicadas o casi erradicadas en 
El Salvador, han comenzado a reaparecer y a transmitirse con mayor frecuencia. La incidencia de casos sospechos de tuberculosis está incrementándose. Desde 1980 a 1981, el número de casos de sarampión registrado aumentó en 550 por ciento. En 1989, se registraron 13,753 casos de sarampión, con lo cual El Salvador es el país centroamericano con más casos registrados de sarampión. Durante los primeros nueve meses de 1990 , se registraron 860 casos de sarampión ${ }^{35}$. Estas cifras reflejan una subestimación de la incidencia de la enfermedad; muchos casos nunca son informados al Ministerio de Salud y Asistencia Social. A pesar de los datos disponibles, el ministerio negó la existencia de una epidemia en 1989.

Durante el periodo 1980-1981, el número de casos de tosferina aumentó en el 324 por ciento, el de tifoidea aumentó en el 273 por ciento y el de casos varicela el 93 por ciento ${ }^{36}$. La desnutrición y las enfermedades diarréicas debilitantes alcanzaron niveles epidémicos entre las poblaciones de desplazados; el parasitismo intestinal era común. También han surgido brotes epidémicos de dengue hemorrágico y de paludismo en ciertas regiones geográficas durante la última década. Se registraron aumentos en el número de casos de enfermedades relacionadas con la desnutrición, por ejemplo, la anemia entre las mujeres embarazadas.

El SIDA (Síndrome de Inmunodeficiencia Adquirida) es una enfermedad transmisible que podría llegar a proporciones alarmantes en El Salvador. Esta enfermedad se transmite principalmente por la sangre y los productos sanguíneos. Los hábitos sexuales y la promiscuidad también constituyen un factor importante en su propagación. Las personas pueden ser infectadas y convertirse en transmisores de la enfermedad sin que sepan de su estado ni sientan los síntomas durante mucho tiempo.

Según recientes declaraciones del Ministro de Salud, el número de casos de SIDA registrados en el país ha aumentado en un 30-33 por ciento. De acuerdo a las estadísticas oficiales, en el país se han comprobado 357 casos de SIDA, desde finales de 1985 hasta julio de 1991. De ese total, 198 casos se ubicaron en el área metropolitana de San
Salvador, 39 en la zona occidental y 19 en la zona oriental. Las áreas urbanas presentan mayor porcentaje de infectados (74 por ciento). Según el Ministerio de Salud, la enfermedad ha cobrado 68 muertes en El Salvador hasta 1991. Por cada persona infectada, se estima que otras cien corren el riesgo de ser "portadoras del virus." A finales de la década, cuatro de cada cinco salvadoreños, o sea, el 80 por ciento de la población, podría ser portador del virus del SIDA. Esta proyección podria revertirse sólo si la población practica las medidas preventivas y si hay cuidados adecuados para tratar y controlar la enfermedad entre las personas infectadas. "El número de personas contagiadas se duplicará cada año," según Juan José Fernández, encargado de la unidad de epidemiología de la infección por SIDA del Hospital Rosales.

\subsubsection{La desnutrición}

A cada gobierno corresponde lograr que sus habitantes alcancen un nivel mínimo aceptable de alimentación y así evitar altos grados de desnutrición y enfermedades. Sin embargo, El Salvador es uno de los países centroamericanos con mayores niveles de desnutrición, a tal grado que ha llegado a ubicársele entre los países que conforman el cinturón mundial del hambre ${ }^{37}$. Según el Banco Mundial, la desnutrición de niños menores de cinco años en El Salvador sobrepasa el 50 por ciento en la actualidad, una tasa mayor que la de Haití (30 por ciento) y Honduras ( 35 por ciento) ${ }^{38}$.

Unos dos millones de salvadoreños "no comen regularmente". Según datos del Ministerio de Salud Pública y Asistencia Social, en 1989, el 75 por ciento de los niños menores de cinco años sufre de desnutrición y el 43 por ciento de las mujeres embarazadas sufre de anemia. Aproximadamente, el 30 por ciento de los niños menores de cinco años tiene un retardo en el crecimiento físico, y hay áreas rurales con retardo de crecimiento (talla) entre el 50 y el 70 por ciento. Los mayores niveles de desnutrición se encuentran en la población que habita las zonas rurales y las comunidades marginales de las zonas urbanas. Unos 300,000 niños muestran deficiencias de vitamina A. 


\section{Los servicios de la salud en El Salvador}

Ya por los affos setenta, existian cinco diferentes formas y niveles de servicios de salud en El Salvador. Fuera y dentro del país se podían enconurar servicios privados de salud, así como también se podía pertenecer al sistema del seguro social (Instituto Salvadoreño del Seguro Social); los trabajadores y el público en general podian acudir al sistema general de salud, o recurrir a los cuidados proporcionados por un estudiante de medicina, sin licencia para ejercer, o buscar un curandero o un trabajador empírico de la salud. En la actualidad, todos estos niveles siguen existiendo, pero con modificaciones significativas en cuanto a la proporción de los servicios privados ofrecidos dentro del país. Para las personas con recursos económicos, hay mayores y mejores servicios de salud disponibles, pero no para las mayorías populares.

El sistema privado está orientado al beneficio económico; posee su propia infraestructura y cuenta con clínicas y hospitales, que atienden sectores de la población con diferente capacidad para pagar. Este sistema se concentra en los centros urbanos y, específicamente, en el área metropolitana de San Salvador, donde hay mayores posibilidades de beneficios económicos.

Hay otras instituciones que se pueden considerar privadas, pero sin fines de lucro, como la Cruz Roja Salvadoreffo, la Cruz Verde, los programas de carácter religioso y los servicios de salud ofrecidos por varios organismos populares y las organizaciones no gubernamentales locales e internacionales. El 7 de julio de 1991, el arzobispo de San Salvador, Mons. Rivera Damas, dijo, al inagurar una clínica patrocinada por la Iglesia, ubicada cerca de la Basflica del Sagrado Corazón de San Salvador, que la Iglesia estaba dispuesta a dar cuidados de salud, pero advirtió que "esto es realmente una obligación del Estado".

El sistema público está compuesto por instituciones que tienen como fin prestar servicios de salud a la población salvadorenfa, financiadas por el Estado en forma total o parcial. Incluye hospitales, unidades, centros y puestos de salud del Ministerio de Salud Pública y Asistencia Social. También hay un hospital de ANTEL y varias ins- talaciones del seguro social, financiadas mediante aportaciones obrero-patronales, para uso de los trabajadores de la empresa privada y empleados del Estado, que contribuyen ${ }^{39}$. E1 85 por ciento de la población necesita una cobertura de servicios de salud preventiva, consulta externa, hospitalización y suministro de medicamentos de una forma gratuita, debido a sus bajos ingresos. La población que está bajo la protección del Ministerio de Salud Pública crece a un ritmo bastante acelerado, pero los recursos de éste no crecen al mismo ritmo, tanto en recursos humanos como en infraestructura. Por lo tanto, cada vez es más grande el déficit de satisfacción de esta necesidad vital para la población, a pesar de que el número de médicos y camas ha aumentado en los anos recientes ${ }^{40}$. En todo esto, hay confusión de los roles formativo, financiero y ejecutor del Estado.

Dado el deterioro marcado del sistema público de salud, solamente el 37 por ciento de la población salvadoreña tiene acceso a estos servicios, según el Ministerio de Planificación. El sector privado ha proliferado para cubrir algunas de las necesidades $y$, como es natural, los hospitales, los consultorios y las instituciones con fines de lucro ofrecen mejores servicios y producen beneficios económicos considerables't

Un estudio reciente sobre la demanda de servicios de salud muestra que, en la práctica, la población hace uso de los servicios de salud de diferente manera ${ }^{42}$. Los servicios públicos de salud son tan malos que una parte de la población busca servicios en el subsector privado y en otras instituciones ${ }^{43}$.

Cuadro 4

Servicios de salud (en porcentaje)

\begin{tabular}{llcc}
\hline & Teórica & $\begin{array}{c}\text { Práctica } \\
\text { Consulta } \\
\text { externa }\end{array}$ & $\begin{array}{c}\text { Práctica } \\
\text { hospitali- } \\
\text { zación }\end{array}$ \\
\hline Ministerio de Salud & 80 & 39.7 & 75.5 \\
Seguro social & 12.5 & 12.7 & 12.6 \\
Subsector privado & 7.5 & 45.2 & 9.4 \\
Otras instituciones & & 2.3 & 2.5 \\
\hline
\end{tabular}


El gobierno promueve intervenciones específicas y selectivas, de corta duración. Promueve intervenciones con resultados relativamente inmediatos, muy visibles, y cuantificables. Por ejemplo, promueve las campanas nacionales de vacunación y da mucha publicidad al número de niños vacunados, pero pone menos cuidado en asegurar que cada una de las personas de una categoría de alto riesgo, por ejemplo los niños menores de un afio de edad, de 1-4 años de edad y las mujeres embarazadas, reciba una serie completa de inmunizaciones y así sea protegido contra las enfermedades inmunoprevenibles. Alrededor de las campañas de vacunación se ha desarrollado una mística que las pone fuera del alcance de la crítica. Los resultados producidos son medibles, no son muy caras en relación con otras intervenciones estatales y son atractivas para los trabajadores de la salud, los políticos y el pueblo en general.

Sin embargo, los recursos humanos y económicos necesarios para llevar a cabo una campaña nacional de vacunación son asignados en menoscabo de la tarea más ardua de planificar y dotar de servicios primarios de salud continuos y eficaces a esa misma población vacunada. Por ejemplo, cuesta diez veces más asegurar que un niño llegue a crecer y a convertirse en adulto que proporcionarle la serie completa de inmunizaciones. La pobreza hace retroceder los avances logrados por las campañas de vacunación. La calidad de vida que los niños confrontan deja mucho que desear, no siendo suficiente vacunarlos. Es necesario examinar la calidad de vida que llevan.

\subsection{Los recursos económicos}

Dadas las obligaciones y responsabilidades asumidas por el Estado, el gobierno tiene ciertas alternativas para garantizar que las necesidades básicas de las mayorías sean cubiertas. Sin embargo, no se asignan suficientes recursos económicos al sistema público de salud y hay, además, una mala distribución y un mal uso de los recursos asignados y recibidos de la ayuda internacional.

El "Plan nacional de salud, 1991-1994", enmarcado en el "Plan nacional de desarrollo económico y social" así como las políticas de corto y mediano plazo del gobiemo tienen como objetivo general "fomentar, proteger y restaurar la salud de la población"44. Pero de hecho, desde 1981, las asignaciones presupuestarias al Ministerio de Salud Pública han disminuido en más del 50 por ciento, dificultando poder pagar los salarios y prestar los servicios de salud. En 1990, el gobierno inició una política de mayor austeridad, acompañada de programas de ajuste estructural y de privatización. Con el pretexto de reducir el presupuesto estatal, de recortar el déficit fiscal y de salir de varias obligaciones y responsabilidades asumidas por el Estado, es casi imposible pensar en un aumento de los fondos gubernamentales para los servicios públicos de salud por parte de este gobiemo.

Hace dos décadas, el Ministerio de Salud Pública comentó que el presupuesto asignado a salud en los últimos años equivalía al 10 por ciento del presupuesto nacional, habiéndose gastado entre nueve y diez colones por persona al afio - menos de tres centavos diarios por persona-, el gasto más bajo per cápita de Centroamérica ${ }^{45}$. Ahora, veinte años después, el presupuesto para la salud es de 404.8 millones de colones, un promedio de 75 colones (9.40 dólares) por persona al año, equivalente a 0.2 centavos por persona al día. Esta cantidad representa sólo el $0.7 \%$ del PIB, ¡una de las tasa más bajas del mundo! Representa el 8.1 por ciento del presupuesto nacional, a pesar de que hace doce años, en 1979, la salud recibió el 16.5 por ciento del presupuesto nacional.

Al mismo tiempo, las asignaciones presupuestarias para la defensa y la seguridad pública subieron del 14.2 por ciento en 1979 , hasta el 35.9 por ciento en 1986, y el 22.8 por ciento del presupuesto nacional de 1991. El presupuesto nacional para la defensa y la seguridad es de 1,135.6 millones de colones en 1991, un promedio de 224 colones por persona al año (28 dólares). ¡Una asignación tres veces más alta que la asignación para la salud! Estos datos sobre las asignaciones presupuestarias para la defensa, no incluyen los montos de la ayuda militar.

En un documento de 1985, preparado por el gobiemo estadounidense, se dice que "los gastos 
militares han limitado la disponibilidad de recursos de los programas para mantener los niveles de vida, para promover los servicios sociales y para enfrentar los problemas humanitarios" ${ }^{146}$.

El gobierno de El Salvador ha recibido múltiples donaciones, préstamos y se há beneficiado de programas de ayuda internacional, los cuales no pueden cuantificarse fácilmente por su carácter vertical. En la práctica, la mayor parte de los fondos para los programas gubernamentales se destinan para cubrir los gastos del aparato estatal, llegando muy poco de ellos a los supuestos beneficiarios. Los recursos financieros proporcionados por los organismos internacionales no son utilizados eficientemente por el gobierno salvadoreño. El presupuesto del Ministerio de Salud Pública también depende significativamente de la cólaboración de los patronatos de salud, lo cual, en 1990-1991, significó 16.5 millones de colones, el 4 por ciento del presupuesto nacional asignado a salud. Por otro lado, la corrupción impide el desarrollo de los servicios de salud. El gobierno estadounidense informó sobre un caso en el cual habia participado la sección del Ministerio de Salud Pública dedicada a la compra y distribución de medicinas y de equipo médico ${ }^{47}$.

Para implementar sus recientes programas de ajuste estructural, el gobiemo busca activamente préstamos y donaciones de los gobiernos amigos, con los cuales atender a las necesidades de la salud pública. En junio de 1991, el Fondo de Inversión Social recibió 375,000 dólares para financiar la construcción de un puesto de salud en San Ramón (Mejicanos) y una escuela de educación especial para 150 niños en San Salvador. Este Fondo de Inversión Social ejecutará otros proyectos de desarrollo a través de las municipalidades. El Fondo de Inversión Social ha sido establecido por cuatro años, es decir, para el tiempo que ARENA esté en la presidencia. Aunque su orientación aparente es social, todos los proyectos que se están implementando a través de este fondo son claramente de carácter político.

En algunas circunstancias, los servicios de salud están politizados. Por ejemplo, en 1991, la AID y el "Programa de salud materno infantil" se negaron a entregar fondos a unas fundaciones, alegando que tenían tendencias políticas opositoras, pese a la viabilidad técnica y a la necesidad de los programas de salud que dichas fundaciones presentaron.

\subsection{La infraestructura}

El uso deficiente de los recursos y del equipo impide el desarrollo de los servicios de salud. Aproximadamente, el 90 por ciento del presupuesto ordinario del Ministerio de Salud Pública del año 1990-1991 se dedicó a programas de funcionamiento y el resto a programas de inversión ${ }^{48}$.

$\mathrm{Al}$ igual que muchos otros países en vías de desarrollo, El Salvador asigna una buena cantidad del presupuesto de salud a los hospitales públicos urbanos. En 1987, el 40 por ciento del presupuesto del Ministerio de Salud Pública fue asignado a los catorce hospitales urbanos, mientras que los otros 338 establecimientos públicos de salud compartieron el 60 por ciento restante. Mientras se inauguran hospitales especializados, capaces de hacer operaciones de corazón abierto, accesibles a un reducido número de pacientes, la mayoría de los niños menores de cinco años que mueren, fallecen por enfermedades transmisibles y prevenibles. Aunque el 56.87 por ciento de la población salvadoreña vive en zona rurales, la mayoría de los centros de salud están ubicados en el área urbana.

Muchos de los centros de salud se encuentran sin medicamentos, sin equipos y sin materiales. Algunos han sido completamente abandonados. El sistema de puestos de salud, de unidades de salud y de clínicas públicas rurales es rudimentario e inadecuado. Los hospitales regionales y los puestos de salud existentes no están equipados ni capacitados para atender muchas enfermedades. Desde hace más de una década, los pacientes tienen que llevar su propio papel higénico, alimentos, jabón, materiales quirúgicos, suturas, etc., para una operación. Hay una lista de más de 20,000 personas esperando para poder ser sometidos a cirugía electiva en el Hospital Rosales ${ }^{49}$. Los equipos y los edificios se están deteriorando cada vez más. Están aumentando los problemas de asistencia mé- 


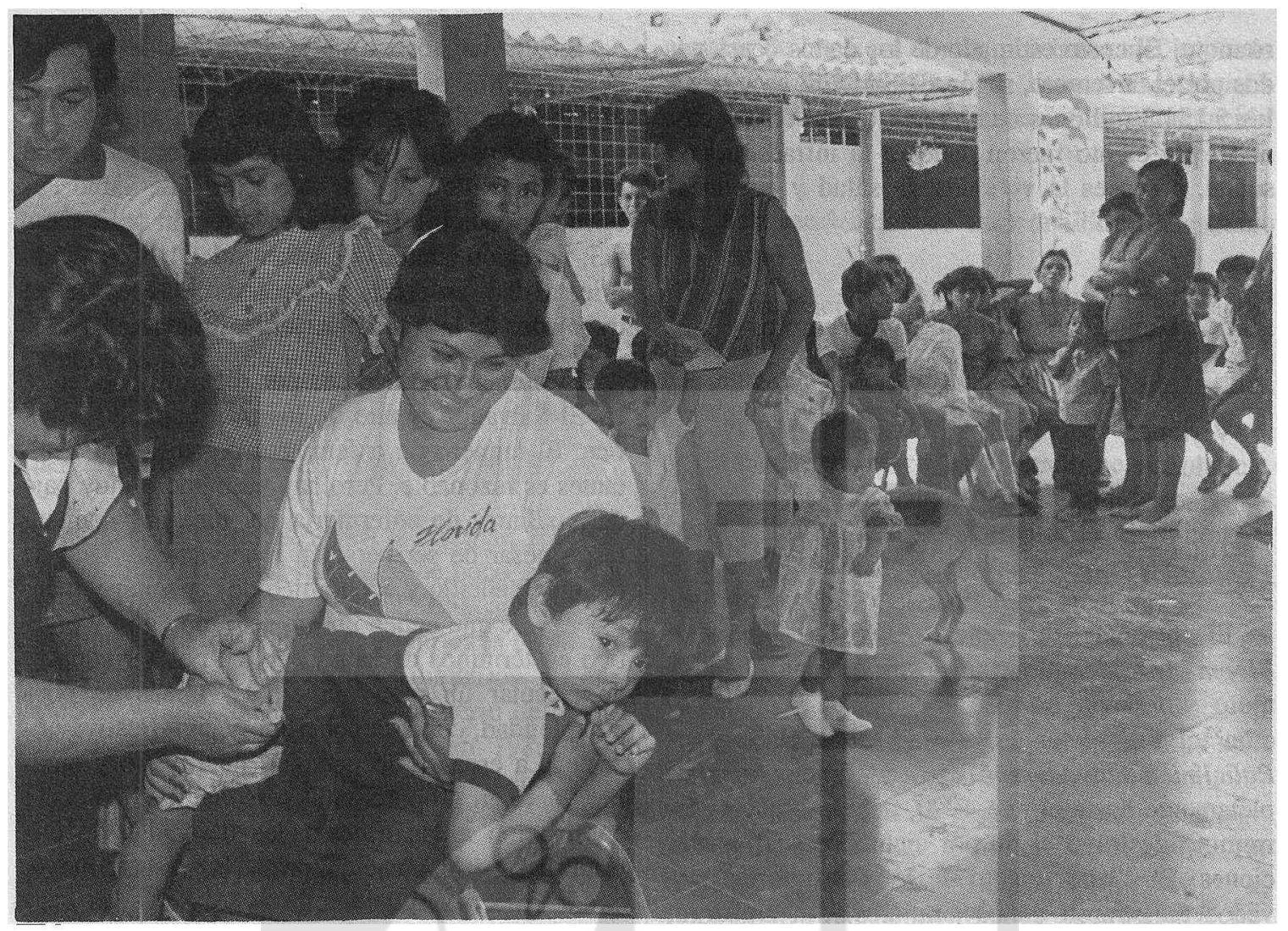

dica y los gastos para pagar las reparaciones costosas que podian haberse prevenido a través de un programa de mantenimiento ${ }^{50}$.

\section{Cuadro 5}

Establecimiento de salud (1971-1991)

\begin{tabular}{lcc}
\hline Establecimiento & $\begin{array}{c}\text { Número } \\
1971-72\end{array}$ & $\begin{array}{c}\text { Total } \\
1990-91\end{array}$ \\
\hline Hospitales públicos & 14 & 15 \\
Centros de salud & 19 & 15 \\
Unidades de salud & 65 & 132 \\
Puestos de salud & 95 & 44 \\
Puestos de vacunación & 1 & \\
Dispensarios & & 7 \\
Total & 194 & 387 \\
\hline
\end{tabular}

La población rural debe trasladarse hasta el área metropolitana de San Salvador para recibir tratamiento médico para muchas de sus enferme- dades serias. De esta forma, la población rural, relativamente la más pobre, tiene que invertir más tiempo y más dinero para encontrar un tratamiento adecuado para sus enfermedades.

\subsubsection{Los daños causados por el terremoto}

Varias instalaciones del sistema público de salud fueron dañadas, y aún permanecen cerradas, debido al terremoto del 10 de octubre de 1986. El terremoto provocó cientos de miles de damnificados en la capital, más de mil muertos, diez mil heridos, y 200 mil damnificados ${ }^{51}$.

Debido a que muchos de los establecimientos de salud están concentrados en el área metropolitana de San Salvador, el área que sufrió los danos mayores a raiz del terremoto, los servicios de salud resultaron afectados desproporcionadamente. El sector público de salud sufrió la mayor parte de los estragos, limitando su capacidad para brindar atención a la población durante y después del te- 
rremoto. El costo estimado de los daños ocasionados por el terremoto, según FUSADES, asciende a los 5,154.8 millones de colones, de los cuales casi el 50 por ciento fueron daños a la infraestructura social, como es la vivienda, la salud y la educación.

\section{Cuadro 6}

Daños causados por el terremoto (Millones de colones)

\begin{tabular}{lc}
\hline Vivienda & $1,367.1$ \\
Salud & 444.7 \\
Educación & 338.7 \\
Total & $2,150.50$ \\
\hline
\end{tabular}

El hospital de niños, Hospital Benjamín Bloom, por ejemplo, fue destruido por el terremoto y todavía está en proceso de reconstrucción $^{52}$. En el sector privado de salud, el Hospital Policlínica Salvadoreña dejó de funcionar completamente hasta el año 1990 , debido a que el terremoto destruyó el 60 por ciento de sus instalaciones. El 22 por ciento de los consultorios privados registraron daños similares. Sin embargo, una cantidad considerable de recursos, provenientes de diferentes programas de la ayuda internacional, fueron recibidos por el Ministerio de Salud Pública para la reconstrucción de la infrastructura dañada y para la reposición de equipos y materiales de salud.

\subsection{Los recursos humanos}

En El Salvador faltan recursos humanos capacitados para la salud, pero el problema principal es la mala distribución de los recursos humanos que existen. Muy pocos médicos salvadoreños trabajan en las zonas rurales, debido a una serie de factores: las pobres condiciones de vida, los bajos ingresos y la inseguridad personal, causada por la desconfianza y el hostigamiento de las autoridades locales hacia los trabajadores de la salud. La falta de infrastructura, equipo, materiales, medicamentos, etc., para poder llevar a cabo su trabajo, también reduce el interés de muchos profesionales de la salud para trabajar en las zonas rurales.
En un diagnóstico de la situación de la salud del año 1963, se detectó una desproporción en la distribución de los trabajadores de salud en el país. El departamento de San Salvador tenía ocho trabajadores de salud del Ministerio de Salud Pública por cada mil habitantes; la región occidental, 2.3; la región central y paracentral 1.1; y la región oriental $\mathbf{0 . 8}$, es decir, ni siquiera contaba con un trabajador de la salud por cada mil habitantes ${ }^{53}$.

El número de médicos por diez mil habitantes en El Salvador es uno de los más bajos de América. El numero de enfermeras por diez mil habitantes es razonable. Pero hay un número muy bajo de auxiliares de enfermería por diez mil habitantes, a pesar de ser personal relativamente fácil de reclutar, sencillo y económico de capacitar y mantener, y de que tienen un impacto muy alto y práctico en términos de salud pública por ser capaces de ejecutar un gran número de tareas de poca complejidad, con alta cobertura y significativa eficacia. La escasez de personal intermedio y auxiliar, tanto en proporción al personal médico como en relación a las necesidades derivadas de una prioridad en la atención primaria, resulta mayor que la de personal médica ${ }^{54}$.

La mayoría de los trabajadores del Ministerio de Salud Pública está concentrada en las áreas urbanas; hay un promedio de 4 médicos por cada 10,000 habitantes en el pais, pero en las zonas rurales se llega a situaciones de tener un médico por cada 50,000 habitantes. Esta situación ha existido desde hace años. En 1978, el 70 por ciento de todos los médicos vivía en San Salvadors5. En 19711972, había 2.3 trabajadores de salud del Ministerio de Salud Pública por cada 100 habitantes, una proporción que prácticamente no ha variado desde el año de $1962^{56}$. Desde entonces, las cifras han disminuido y la proporción de trabajadores de salud por cada mil habitantes es menor ahora que hace dos décadas. Comparativamente, hay $9.5 \mathrm{mi}$ litares por cada mil habitantes en El Salvador.

En 1962, se registraron 38 consultas médicas por cada cien habitantes; en 1970, 40; en 1986, 60 ; y en 1990,62 . La proporción de las consultas médicas por cien habitantes varía según la región. En la región occidental era de 36; en la central, 


\section{Profesionales por diez mil habitantes}

\begin{tabular}{lccc}
\hline & 1978 & 1985 & Preferible \\
\hline Médicos & 3 & 3.2 & 5 \\
Dentistas & 1 & 0.4 & \\
Enfermeras graduadas & 3 & 2.1 & \\
Enfermeras auxiliares & 6 & & \\
Enfermeras total & & & 5 \\
Camas hospitalarias & 2 & 11.93 & 20 \\
\hline
\end{tabular}

Fuente: Gallardo y López, 1986, pp. 196-197.

27; en la paracentral, 29; y en la oriental, 2357. La población de las zonas rurales tiene poco acceso a una atención médica adecuada. La cantidad de consultas, registradas por los promotores de salud, las parteras, los colaboradores voluntarios, las enfermeras y otros técnicos del Ministerio de Salud Pública, ascendían casi al doble, en 1986, 114 consultas por cada cien habitantes y, en 1990, 107.

No existen servicios de salud, no hay trabajadores de salud y las distancias, los costos y los riesgos de un viaje para buscar atención médica son altos. No es difícil entender, entonces, por qué las tasa de mortalidad y la de morbilidad son tan altas en las zonas rurales. Solamente la tercera parte de la población busca los servicios de salud en caso de diarrea, y solamente el 21 por ciento recurre a un líquido de rehidratación oral. El 81 por ciento de los partos en el área metropolitano de San Salvador es atendido por un médico; pero en las zonas rurales, sólo el 25 por ciento de los partos es atendido por un médico; el 50 por ciento es atendido por una partera y el 13 por ciento no recibe ningún cuidado ni atención.

\section{El impacto de la guerra}

En la guerra actual no se respeta el principio de la neutralidad médica. Los trabajadores de la salud, particularmente los de las áreas rurales, son amenazados con la detención y la violencia. Esta situación limita significativamente la capacidad de prestar servicios de los trabajadores de la salud en algunas de las áreas donde, precisamente, hay más necesidad, to cual, a su vez, lleva a una mortalidad y morbilidad innecesarias entre la población civil.

\subsection{Las tendencias de la morbilidad y morta- lidad}

La violencia política ha sido una causa significativa de mortalidad desde el año de $1980^{58}$. En los once affos de guerra se han producido $70 \mathrm{mil}$ muertes y miles de heridos.

El conflicto bélico ha afectado negativamente los esfuerzos para reducir y controlar las enfermedades transmisibles, por lo tanto, la morbilidad y la mortalidad, debidas a estas enfermedades, pueden aumentar en ciertas áreas geográficas. Por ejemplo, la entrega de vacunas a niños menores de cinco anfos y a las mujeres embarazadas que viven en las zonas conflictivas ha sido obstaculizada en varias ocasiones. Los trabajadores de la salud sólo pueden penetrar en estas zonas y administrar dichas vacunas cuando se negocia un cese del fuego temporal, el cual no siempre es respetado. En 1989, un equipo de trabajadores de la salud de la diócesis de Chalatenago que llevaba vacunas fue capturado por soldados en La Laguna. Durante la campaña nacional de vacunación del $\mathbf{1 0}$ de febrero de 1991, un artefacto explosivo cerca de un retén militar en Osicala (Morazán), cuando los trabajadores de salud del Ministerio de Salud Pública y de otras instituciones humanitarias estaban detenidos por dicho retén. Los trabajadores de la salud decidieron retirarse y las vacunas nunca llegaron a las comunidades del norte de Morazán ${ }^{59}$.

En las áreas nurales, la instalación y el mantenimiento de los sistemas de agua potable y de letrinas es frecuentemente impedido por las restricciones militares. La Fuerza Armada, argumentando que la tubería, el cemento, el hierro y los otros materiales de construcción son confiscados por la guerrilla y utilizados para hacer armamento casero, no permite fácilmente el ingreso de los materiales necesarios para los sistemas de agua y las medidas de saneamiento ambiental. Tales restricciones tendrán un impacto negativo muy significativo frente a una epidemia de cólera. 


\subsection{Los ataques contra los trabajadores de salud}

Durante el conflicto bélico, los servicios de salud han sido afectados por la renuncia de trabajadores de salud, la renuncia o la suspensión temporal del trabajo en los establecimientos de salud y en las comunidades, y por el exilio, voluntario $o$ no, de numerosos trabajadores de salud.

En las décadas de los sesenta y de los setenta, en las comunidades rurales se establecieron redes informales de promotores de salud. Las comunidades establecieron pequeños puestos y botiquines para prestar servicios de salud a sus miembros. Esta labor fue apoyada de manera decidida por la Iglesia católica, las cooperativas y por otras instituciones humanitarias y por organizaciones no gubernamentales. Sin embargo, muy pronto y a lo largo de la década de los ochenta, los trabajadores de la salud, los delegados de la palabra, los catequistas, los cooperativistas y otras personas comprometidas con la ayuda humanitaria a las poblaciones necesitadas fueron víctimas de la represión. Al terminar la década, muchos de los promotores de la salud y de los trabajadores de la Iglesia, los cooperativistas y miembros de las organizaciones no gubernamentales que apoyaban los programas alternativos de salud fueron hostigados, amenazados y capturados. Algunos de ellos fueron asesinados. Muchos trabajadores de la salud huyeron del país en la década pasada. Asimismo, varios profesionales de la salud extranjeros fueron obligados a salir de El Salvador en 1989.

Ahora, una década después, confrontando condiciones de salud peores y una carencia de servicios de salud frente a unas necesidades alarmantes, varias iglesias, organizaciones no gubernamentales, sindicatos y organizaciones populares intentan cubrir dichas necesidades. Su trabajo tiene fines humanitarios. Frecuentemente, estos trabajadores y promotores de la salud se encuentran trabajando en los sectores pobres de las zonas rurales y urbanas, donde no existen servicios públicos de salud o donde éstos son inadecuados, demasiados costosos o no funcionan.

Al proporcionar servicios primarios de salud a la población, se van creando una demanda y unas expectativas para que hayan unas estructuras sociales más justas. Frecuentemente, los programas de salud han sido focos de organización comunitaria. El gobierno y la Fuerza Armada han reaccionado tratando de reprimir los programas de salud implementados y controlados por las comunidades y los sectores populares, o absorbiéndolos en los programas gubernamentales, controlados de manera centralizada Los promotores de la salud y los demás trabajadores de la salud están siendo blanco de restricciones, amenazas, campañas de difamación y capturas. Por ejemplo, por parte de la Fuerza Armada no existe ninguna disposición para permitir a los trabajadores de la salud extranjeros trabajar con ciertas poblaciones, como las de los desplazados, los repobladores y los repatria$\operatorname{dos}^{60}$.

\subsection{Los efectos sobre servicios de salud}

Durante la ofensiva del FMLN, en noviembre de 1989 , varias clínicas parroquiales y varios proyectos comunitarios de salud fueron cerrados durante muchos meses; el hospital regional de Zacatecoluca estuvo cerrado cerca de un año y algunas clínicas rurales fueron cerradas indefinidamente. Los programas de salud en más de 400 comunidades también fueron cerrados. El acceso a los heridos y detenidos fue obstaculizado. Los programas de entrenamiento para los trabajadores de salud, incluyendo el programa de la Universidad de El Salvador, y varios programas de capacitación de las iglesias, de las organizaciones no gubemamentales y de las comunidades de repatriados y repobladores, fueron asimismo cerrados por intervenciones militares, arrestos, amenazas, interferencia en el acceso a las comunidades que servían, o temor de que sus actividades de capacitación en la salud fueran a ser interpretadas como una acción ilegal durante el estado de sitio, impuesto desde noviembre de 1989 hasta abril de $1990^{61}$.

El conflicto bélico ha tenido otros efectos negativos sobre los cuidados de salud la población. Los envíos de alimentos, medicinas, equipo y materiales médicos, y otros artículos para cubrir las necesidades básicas de la población desplazada y repatriada frecuentemente son obstaculizados y hasta confiscados. Las restricciones militares para 
acceder a las zonas rurales tienen un fuerte impacto negativo en el suministro de medicamentos, equipo y materiales médicos, y en la movilización de trabajadores de la salud y de pacientes, particularmente en las zonas rurales. Todo ello entorpece el desarrollo de los programas de capacitación de los promotores de la salud. La exigencia de portar un salvoconducto del Estado Mayor de la Fuerza Armada o un permiso del comandante local, además de ser innecesaria e illegal, es un serio obstáculo para la salud de las poblaciones de las zonas rurales conflictivas.

\subsection{La infraestructura de salud}

Según el Ministerio de Salud Pública, 46 (8.4 por ciento) de los 387 establecimientos de salud todavía estaban cerrados en 1991, debido al conflicto armado. El 25 por ciento de los establecimientos cerrados está en la región oriental del país.

El principal centro de entrenamiento para profesionales médicos, la Universidad de El Salvador, ha sido cemado en varias ocasiones -en 1977 , de junio de 1980 a mayo de 1984 , y de noviembre de 1989 a junio de 1990 . A pesar de que durante estos cierres, las facultades de la universidad trataron de seguir desarrollando sus programas en otras localidades, no interrumpiendo así la preparación de nuevos médicos. Durante el cierre de 1980 a 1984 , las facultades de odontología y medicina fueron intervenidas por el ejército y sus dependencias fueron registradas, saqueadas y casi destruidas. En varias ocasiones, el ejército ha puesto retenes en los alrededores de la universidad, impidiendo las actividades académicas.

En la última década, una amplia gama de universidades privadas ha aparecido, ofreciendo, algunas de ellas, las carreras de medicina, enfermería y otras profesiones de salud. En general, las universidades privadas no son accesibles a los estudiantes de bajos recursos y han producido muy pocos profesionales de la salud.

Por otro lado, ha aparecido y se ha desarrollado toda una rama de salud militar. Los hospitales militares reciben fondos del Ministerio de Defensa y apoyo intemacional; tienen mayores recursos per cápita disponibles que el sistema público de salud. Estos hospitales dan servicios médicos de salud y los 55,000 miembros de la Fuerza Armada y sus dependientes, cubriendo asi aproximadamente el 3 por ciento de la población. El Hospital Militar San Luis de San Salvador fue construido a un costo de 16.3 millones de colones, con 300 camas, pero no está siendo utilizado ${ }^{62}$.

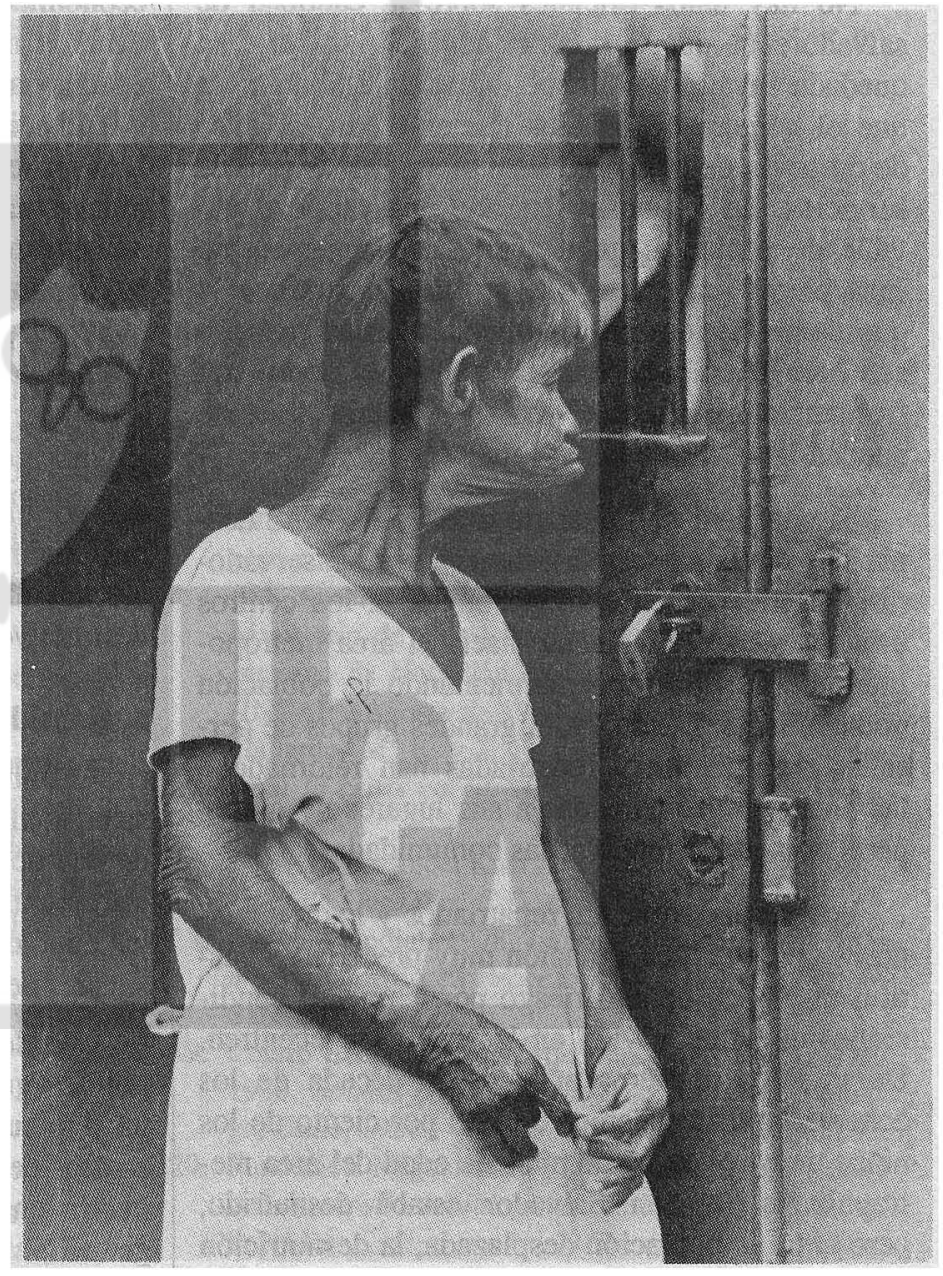


5.5. Los derechos humanos durante un conflicto armado

Como resultado del conflicto armado han aparecido tres fenómenos con repercusiones significativas en el perfil de la salud del pueblo salvadorefio: aumento de la tasa bruta de mortalidad, debido a los enfrentamientos y a otras acciones armadas; migraciones y desplazamientos de poblaciones civiles en las zonas conflictivas, y el asentamiento de grandes poblaciones de desplazados en las zonas urbanas marginales. El terremoto del 10 de octubre de 1986 generó otra cantidad enorme de desplazados dentro del área metropolitana de San Salvador.

No hay datos oficiales sobre la cantidad de salvadoreflos que, a raíz del conflicto armado, ha quedado inválido. No cabe duda, sin embargo, de que el número de lisiados aumenta con los años de duración de la guerra. Este sector aún carece de servicios. En los hospitales hay una cantidad notable de pacientes que han perdido un miembro (una piema, un brazo, etc.) a raíz del conflicto o que tienen heridas en sus miembros. Las víctimas con heridas en la cabeza, el cuello y el pecho con frecuencia mueren en el campo de batalla, pues no pueden llegar hasta los hospitales ${ }^{63}$.

El conflicto ha generado más de 500,000 desplazados internos, según estimaciones conservadoras. Muchos de ellos migraron hacia los centros urbanos y específicamente hacia el área metropolitana de San Salvador, aumentando la población notablemente. Desde 1986, grandes grupos de personas desplazadas y repatriadas han retomado a las áreas rurales cercanas a sus lugares de origen para asentarse y repoblar las comunidades.

Los desplazados, los repatriados y los repobladores viven eầ una situación muy precaria y constituyen grupos de alto riesgo por las malas condiciones de salud y vida en las que se encuentren. Durante los primeros años de la década de los ochenta, aproximadamente el 50 por ciento de los niffos menores de cinco af́os de edad del área metropolitana de San Salvador estaba desnutrido, gero entre la población desplazada, la desnutrición afectaba al 70 por ciento. La falta de agua potable, de servicios sanitarios, de una nutrición adecuada, de condiciones adecuadas de vida y la extrema pobreza de esta población la hace muy susceptible a las principales causas de mortalidad: las enfermedades respiratorias y la diarrea.

Este fenómeno de desplazamiento y migración también llevó al colapso del sistema nacional de infraestructura de salud, el cual no ha podido enfrentar y cubrir las grandes necesidades actuales. La forma y la cantidad de la asistencia internacional para la salud de los desplazados aumentó en la década pasada, pero aún así, no ha sido suficiente para hacer frente a las necesidades.

Los gastos para la defensa y la seguridad nacional están afectando negativamente el desarrollo económico. La inversión en armas y en la militarización no contribuye al crecimiento económico. La desviación de fondos para usos sociales y civiles hacia gastos militares estimula la inflación. Los gastos militares de El Salvador aumentaron mucho más rápidamente que el PIB. Las inversiones en el sector militar no sólo impiden el desarrollo, sino que lo paralizan.

Los riesgos de la población que vive en medio del conflicto bélico provienen no sólo de la violencia causada por las armas, sino también de los efectos sociales, económicos y políticos, generados por el mismo conflicto. Estos efectos, a veces más indirectos y más lentos para manifestarse, afectan al tejido social y hasta pueden ser más destructivos que el propio conflicto armado.

\section{Consideraciones finales}

El Salvador es un ejemplo de lo que pasa a la salud y al bienestar de una nación en condiciones de una negligencia casi total. Muestra la injusticia estructural. Por lo tanto, es necesario replantearse las condiciones de salud del país, desde las necesidades de las mayorias populares pobres.

Una de las características más relevantes de la política gubernamental salvadoreña durante anos, ha sido su falta de atención sobre las necesidades básicas de la población. El sector de salud pública ilustra una situación de suma gravedad y negligencia. La aparición de una enfermedad mortal transmisible como el cólera mostrará empiricamente lo que estamos diciendo, y, a la vez, pro- 
porcionará una oportunidad para reflexionar y enfrentar el mal manejo y el mal estado de la salud del pueblo salvadoreño.

El gobiemo actual tiene una doble estrategia para combatir la pobreza. Por un lado, proyecta implementar acciones directas de corto plazo y de duración y con resultados obvios. Estas medidas han sido diseñadas para contrarrestar la capacidad reducida del Estado para garantizar los servicios económicos, sociales y políticos básicos, así como para minimizar los efectos negativos de los ajustes estructurales. La segunda estrategia es promover el crecimiento económico, inclusive en el sector privado, con la idea de que el crecimiento económico global beneficiará a los sectores de menores ingresos $\mathrm{y}$, eventualmente, impactará a las capas más pobres de la población.

Hasta cierto punto, las políticas gubernamentales consideran que la mala salud del pueblo salvadoreño se debe a la falta de infraestructura y tecnología, de consultas médicas, de material, de sueros y de hospitales, en lugar de considerarla como un síntoma de la pobreza y de las estructuras sociales injustas. El gobierno argumenta que no hay tiempo ni recursos para hacer un planteamiento comprehensivo de la salud de la población. Sólo quiere unas cuantas acciones en orden a reducir la mortalidad, pero no está dispuesto a suprimir la injusticia estructural para erradicar la mortalidad, la morbilidad y la desnutrición.

La salud es como un proceso, que depende de los conocimientos individuales y colectivos, así como también de un análisis de las prioridades, opciones y alternativas. ¿Qué acciones vamos a promover para mejorar las condiciones de salud de todos? Tenemos los medios y los recursos para mejorar la salud de la población. La calidad y la disponibilidad de los servicios de salud de El Salvador podrian mejorar rápidamente si enfocamos en el problema de manera adecuada.

\section{Notas}

1. Organización Mundial de Salud, en "La situación de la salud en El Salvador. Proceso, 1983, 120: 1521. San Salvador.

2. Organización Mundial de la Salud (OMS). 1973.
Relaciones entre programas de salud y el desarrollo social y económico. Ginebra, p. 9.

3. Ministerio de Salud Pública y Asistencia Social (MSPAS). 1991. Memoria, 1990-1991. San Salvador. Desde 1971 no se ha vuelto a levantar un nuevo censo, a pesar de las migraciones, los desplazamientos y los éxodos del país a raíz del conflicto bélico. Las cifras de población son simples estimados.

4. Organización Mundial de las Salud. 1990. Las condiciones de salud en las América, Volumen II. El Salvador. Pp. 140-146.

5. Centro de Información, Documentación y Apoyo a la Investigación (CIDAI). Universidad Centroamericana "José Simeón Cañas". 1991. San Salvador.

6. El Diario de Hoy, 29 de enero de 1991.

7. MIPLAN. 1986. Proyecto: ELS/78/PO4. Polticas de población: estimaciones y proyecciones de población 1950-2025. San Salvador.

8. CIDAI. 1991.

9. MSPAS. 1991.

10. UNICEF. 1987. Diagnóstico de la realidad nacional.

11. MSPAS. 1972. Memoria. San Salvador.

12. United Nation's Children's Fund Program Committee of the United Nations Economic and Social Council. Country Program Recommendatior: El Salvador, 3 de febrero de 1988.

13. MSPAS. 1972.

14. Primer Censo Nacional de Talla de Escolares, 1988; Informe Final: "Evaluación de la situación alimentaria nutricional en El Salvador" (ESANES88). Asociación Demográfica Salvadoreña (ADS), Ministerio de Salud Pública y Asistencia Social e Instituto de Nutrición de Centroamérica y Panamá (INCAP). Agosto de 1990. San Salvador.

15. Gallardo, M. E. y J. R. López. 1986. Centroamérica: la crisis en cifras. ICA/FLACSO. San José, Costa Rica.

16. Fundación Miguel Kast R. 1988.

17. Urquilla González, C.D. et al. 1988.

18. Banco Mundial. 1978. Informe sobre el desarrollo mundial, citado en Proceso, 1983, 120: 15-21. San Salvador.

19. Centro Latinoamericano de Demografía, CELADE. 1986. Boletín Demográfico, Año XIX, 38, Santiago, Chile, 1986.

20. Fundación Miguel Kast R. 1988. Fundamentación del desarrollo social: sector salud. Tomo IV. San Salvador.

21. Fundación Miguel Kast R. 1988.

22. Feachem, R. G. 1987. "Preventing diarrhoea: what 
are the policy options?" Health policy and planning. 1(2). Pp. 109-117; Wray, N. D. 1986. "Child interventions in urban slums: are we neglecting the importance of nutrition?" $I b ., 1(4)$. Pp. 299-308.

23. MSPAS. 1991; MSPAS. 1990. Plan de acción de supervivencia infantil.

24. Documento de Trabajo 24/06/82-002, Departamento de Ciencias Económicas de la Universidad Centroamericana "José Simeón Cañas" en Proceso, 1983, 1102; UNICEF. 1987. Situación de la nutrición y la salud en El Salvador. San Salvador. Ministerio de Salud Pública y Asistencia Social. Febrero de 1991. Plan nacional de salud 1991-1994, San Salvador.

25. Organización Panamericana de la Salud. 1990. Las condiciones de salud en las América. Volumen II: El Salvador, pp. 140-146. Publicación Científica 524.

26. Ministerio de Salud Pública y Asistencia Social. 1991. Memoria 1990-1991. San Salvador.

27. Hospital Benjamín Bloom, "Ten Primary Causes of Mortality, 1988." San Salvador, en National Central America Health Rights Network (NCAHRN). Health Care and Human Rights in El Salvador. 1989.

28. FESAL-85.

29. El Mundo, 20 de agosto de 1991; Diario Latino, 19 de agosto de 1991.

30. El Mundo, 7 de agosto de 1991.

31. El Diario de Hoy, 9 de mayo de 1991.

32. El Diario de Hoy, 25 de marzo de 1991.

33. Diario Latino, 10 de agosto de 1991.

34. Sanders, David. 1985. The Struggle for Health. MacMillan Publishers, Ltd. Londres.

35. Organización Panamericana de la Salud. Boletín informativo, Programa ampliado de inmunización en las Américas. Año XIII, NN 1, febrero de 1991.

36. USAID, Office of Foreign Disaster Assistance (USAID-OFDA), March 1982, en Goldstein, R. 1986. "El Salvador Medical Aid Project," Health and Human Rights, ICHP/CINPROS. Suiza, Pp. $37-41$.

37. Primer Censo Nacional de Talla de Escolares, 1988; Informe Final: "Evaluación de la situación alimentaria nutricional en El Salvador" (ESANES88). Asociación Demográfica Salvadoreña (ADS), Ministerio de Salud Pública y Asistencia Social e Instituto de Nutrición de Centroamérica y Panamá (INCAP). Agosto de 1990. San Salvador. Proceso, 1983, 11: p. 9, en: Urquila González, C. D.et al., 1988. "Alternativas administrativas para dar respuestas a las necesidades básicas de la población salvadoreña y a la reactivación económica, sector salud: hospitales privados, clínicas particulares, especialidades (niños, ancianos, inválidos)". San Salvador, 1988. Tesis de grado, presentada en Universidad Centroamericana "José Simeón Cañas", Facultad de Ciencias Económicas.

38. "Las medidas de compensación social en Centroamérica." Caballero Z., Elsa Lily. Manuscrito no publicado, abril de 1991.

39. Rivera Arevalo, et al. 1990.

40. Figueroa Trejo, et al. 1988.

41. Proceso, 30 de agosto de 1989 , según estadísticas de MIPLAN.

42. En MSPAS. 1991.

43. Resources for Child Health Project (REACH). 1989. "Estudio de demanda por servicios de salud en El Salvador". AID Contract N ${ }^{2}$ DPE-5927-C-005068-00.

44. MSPAS. 1991.

45. MSPAS. 1972. Memoria.

46. Report by the Comptroller General of the U.S. "Providing Effective Economic Assistance to El Salvador and Honduras: A Formidable Task". GAO/NSIAD-85-02. 3 de julio de 1985. El texto original dice: "los gastos militares han limitado la disponibilidad de recursos para los programas destinados a mantener los niveles de vida, para promover los servicios sociales y para enfrentar los problemas humanitarios. El Departamento de Estado estima que la guerra de El Salvador ha producido pérdidas por 800 millones de dólares, en daños directos a la infraestructura y la producción, además del aumento de los costos militares". Ver CIDAI. 1991.

47. GAO (U.S. General Accounting Office). September 1990. El Salvador: Accountability for U. S. Military and Economic Aid. A Report to the Chairman, Subcommittee on Western Hemisphere Affairs, Committee on Foreign Affairs, House of Representatives. GAO/NSIAD-90-132.

48. MSPAS. 1991.

49. Barry, ya citado antes.

50. MSPAS. 1972.

51. El Salvador, Proceso, 1986, 15: 259.

52. FUSADES. Diagnóstico sacial: Situación actual de las necesidades básicas en El Salvador. San Salvador, diciembre de 1986, p. 36.

53. MSPAS. 1972.

54. Fundación Miguel Kast R.

55. Población y salud. "Seminario taller sobre formulación de la nueva política de población". Septiembre de 1986. 
56. MSPAS. 1972.

57. MSPAS. 1972.

58. Garfield, R. y Pedro Rodríguez. "Health and Health Services in Central America". Journal of the American Medical Association, 16 de agosto de 1985.

59. Oficina de Tutela Legal del Arzobispado, Informe semanal, 15-21 de febreto de 1991.

60. National Council for International Health. 1983. Report of ameeting of U.S. Private Sector Organizations About The Health Needs in El Salvador. Washington.

61. Comisión Intemacional sobre la Neutralidad Mé- dica. 1991. Violaciones a la neutralidad médica: El Salvador. Seattle, Washington.

62. Peña Tovar, A. C., et al. 1989. "Altemativas administrativas para la reactivación económica de $\mathrm{El}$ Salvador, priorizando la satisfacción de las necesidades básicas: Sector salud pública-consulta externa y hospitalización". San Salvador. Tesis presentada en la Universidad Centeroamericana "José Simeón Cañas", Facultad de Ciencias Económicas.

63. National Council for Intemational Health. 1983. Report of a Meeting of U. S. Private Sector Organizations About the Health Needs in El Salvador. Washington D.C. 